\title{
PEMBENTUKAN DAN PERKEMBANGAN HUKUM ISLAM PADA MASA KODIFIKASI DAN IMAM-IMAM MUJTAHID
}

\author{
Hadi Daeng Mapuna
}

Fakultas Syariah dan Hukum Universitas Islam Negeri Alauddin Makassar

\begin{abstract}
:
Islamic law that grows and develops in each period has its own characteristics. Based on these characteristics, scholars form a period of Islamic law. In addition, there are also those who base the division by equating human growth. They share the growth of Islamic law as the growth of human age, that is, from childhood, adolescence, adulthood and so on into old age. This article will present the formation and development of Islamic law in one of the periods that have been passed, namely the codification period and mujathid priests.
\end{abstract}

Keywords:

Islamic Law, Codification, Imam Mujtahid

\begin{abstract}
Abstrak:
Hukum Islam yang tumbuh dan berkembang pada tiap-tiap periode memiliki ciri khas tersendiri. Berdasarkan ciri khas tersebut ulama menyusun periodesasi Hukum Islam. Di samping itu, ada pula yang mendasarkan pembagian itu dengan menyamakan pertumbuhan manusia. Mereka membagi pertumbuhan Hukum Islam sebagaimana pertumbuhan umur manusia, yakni mulai dari masa kanak-kanak, remaja, dewasa dan seterusnya memasuki masa tua. Artikel ini akan mengemukakan pembentukan dan perkembangan Hukum Islam pada salah satu periode yang telah pernah dilalui, yaitu periode kodifikasi dan imam-imam mujathid.
\end{abstract}

Kata Kunci:

Hukum Islam, Kodifikasi, Imam-Imam Mujtahid

\section{A. PENDAHULUAN}

eiring dengan perjalanan waktu, hukum Islam --yang mulai tumbuh dan berkembang sejak masa Rasulullah-- tumbuh dan berkembang secara terus menerus. Pertumbuhan dan perkembangannya melintasi satu periode dan 
masuk ke periode berikutnya. Demikian seterusnya hingga sampai pada masa kini. ${ }^{1}$

Hukum Islam yang tumbuh dan berkembang pada tiap-tiap periode memiliki ciri khas tersendiri. Berdasarkan ciri khas tersebut ulama menyusun periodesasi hukum Islam. Di samping itu, ada pula yang mendasarkan pembagian itu dengan menyamakan pertumbuhan manusia. Mereka membagi pertumbuhan hukum Islam sebagaimana pertumbuhan umur manusia, yakni mulai dari masa kanak-kanak, remaja, dewasa dan seterusnya memasuki masa tua. ${ }^{2}$

Pada masa Rasulullah misalnya, pertumbuhan hukum Islam berlangsung secara baik tanpa hambatan apapun. Hal ini dimungkinkan karena Rasulullah merupakan pemegang otoritas pembentukan hukum Islam. Setiap permasalahan yang timbul atau yang dihadapi oleh masyarakat langsung dijawab oleh Rasulullah, baik berdasarkan petunjuk wahyu maupun hasil musyawarah dengan para sahabat. ${ }^{3}$

Pada masa sahabat, pertumbuhan dan pembentukan hukum Islam dapat dikatakan belum jauh berbeda dengan masa Rasulullah. Para sahabat berusaha melanjutkan dan menerapkan hukum Islam yang telah dituntunkan oleh Rasulullah. Hanya saja mengingat semakin bertambah luasnya wilayah yang membawa konsekwensi bertambahnya permasalahan, para sahabat berusaha mengatasinya dengan caranya masing-masing. ${ }^{4}$ Itulah sebabnya A.A.A. Fyzee --sebagaimana dikutip Anwar Haryono-- mengatakan bahwa zaman ini adalah pelanjutan dari kebiasaan lama secara konsekwen dengan bersemboyan mentaati sunnah. ${ }^{5}$ Demikian pula masa-masa selanjutnya. Hukum Islam dalam pertumbuhan dan perkembangannya memperlihatkan ciri khas untuk setiap zaman.

Bertolak dari asumsi di atas, artikel ini akan mengemukakan pembentukan dan perkembangan hukum Islam pada salah satu periode yang telah pernah dilalui, yaitu

${ }^{1}$ Dalam sejarah pertumbuhan dan perkembangan hukum Islam, para ulama pada umumnya membagi ke dalam lima periode, yaitu; (1) periode Rasulullah, (2) periode Sahabat, (3) periode Tabi'in dan Imam Mujtahid, (4) periode taqlid dan jumud, dan (5) zaman kebangunan kembali. Hamzah Ya'kub, Pengantar Ilmu Syari'ah (Hukum Islam) (Cet. IX; Bandung: CV. Diponegoro, 1995), h. 65-67. Adapula yang membagi periodesasi hukum Islam berdasarkan perbedaan dan keistimewaan serta pengaruhnya dalam suatu masa tertentu. Berdasarkan pandangan itu lahirlah periodesasi sebagai berikut: (1) Hukum Islam pada masa Rasulullah, (2) masa Khulafa' al-Rasyidun, (3) masa setelah Khulafa' al-Rasyidun sampai awal Abad ke II H, (4) masa mulai awal abad II H sampai pertengahan abad IV H, (5) masa mulai pertengahan abad IV H sampai jatuhnya Kota Bagdad, dan (6) masa mulai jatuhnya Bagdad sampai sekarang. Syekh Muhammad Ali As-Sayis, Tarikh al-Fiqh al-Islami. Diterjemahkan oleh Dedi Junaedi dengan judul Sejarah Pembentukan dan Perkembangan Hukum Islam (Jakarta: Akademika Pressindo, 1996), h. 11-12.

${ }^{2}$ Lihat, Syekh Muhammad Ali As-Sayis, Tarikh al-Fiqh al-Islami, h. 11.

${ }^{3}$ Lihat, Dr. Anwar Haryono, S.H., Hukum Islam Keluasan dan Keadilannya (Jakarta: Bulan Bintang, 1987), h. 45.

4 Khalifah Abu Bakar pertama-tama mencari dasarnya dalam Al-Qur'an. Kalau tidak ada, beliau mencarinya dalam sunnah Nabi. Kalaupun tidak dijumpai di sana, beliau bertanya kepada khalayak ramai kalaukalau ada di antara mereka yang pernah mengetahui keputusan Nabi. Bila tidak ada barulah beliau bermusyawarah dengan sahabat-sahabatnya. Umar bin Khattab lebih mengutamakan pertimbangan kemashlahatan. Sementara Ali bin Abi Thalib banyak menggunakan qiyas. Baca misalnya Badran Abu al'Ainain Badran, Ushul Fiqh al-Islamiy (Mesir: Muassasah Syabab al-Jami'ah al-Iskandariyah, t.th.), h. 8. Juga Nasrun Haroen, Ushul Fiqh 1 (Cet. II; Jakarta: Logos Wacana Ilmu, 1997), h. 8. Anwar Haryono, Hukum Islam Keluasan dan Keadilannya, h. 50-55.

${ }_{5}^{5}$ Anwar Haryono, Hukum Islam Keluasan dan Keadilannya, h. 50-55. 
periode kodifikasi dan imam-imam mujathid.

\section{B. PERMASALAHAN}

Bertolak dari latar belakang pemikiran di atas, masalah pokok yang akan dibahas dalam artikel ini adalah "bagaimana pembentukan dan perkembangan hukum Islam pada masa kodifikasi dan imam-imam mujtahid?"

\section{TUJUAN DAN KEGUNAAN}

Uraian ini dikemukakan agar dapat diketahui kondisi obyektif pembentukan dan perkembangan hukum Islam pada masa kodifikasi dan imam-imam mujtahid, termasuk faktor-faktor yang mempengaruhinya. Selain itu akan diketahui pula corak pemikiran imam-imam mujtahid yang muncul pada periode ini.

\section{KONDISI OBYEKTIF HUKUM ISLAM PADA PERIODE INI}

Tatkala Mu'awiyah berkuasa, situasi politik diwarnai dengan pertentanganpertentangan dan perebutan kekuasaan. Hal ini membawa pengaruh yang kurang baik bagi pertumbuhan dan perkembangan hukum Islam. Apalagi pada masa itu, lembaga umara dan ulama telah terpisah. Padahal pada masa sebelumnya, yakni masa khulafa' al-Rasyidun, kedua lembaga ini bersatu dalam diri seorang umara.

Dalam kondisi seperti itu, hukum yang seharusnya dijadikan sebagai rujukan dan tempat kembali bagi pihak-pihak yang berselisih, berubah menjadi alat bagi kepentingan-kepentingan golongan yang sedang berkuasa.6 Akibatnya keadilan sukar diperoleh dari para pemegang kekuasaan. Karena itu masyarakat mencarinya ke tempat lain, yakni kepada ulama yang independen. Hal ini untuk menghindari timbulnya pertentangan-pertentangan yang biasa muncul disebabkan perbedaan posisi politik.

Kecenderungan masyarakat untuk meminta fatwa kepada ulama independen, disamping disebabkan sulitnya memperoleh fatwa hukum yang adil dan bebas dari interest politik, juga karena perhatian pemerintahan $\mathrm{Mu}^{\prime}$ awiyah pada tahun-tahun awal sebagian besar tersita pada urusan-urusan peperangan dengan negara-negara lain, khususnya Byzantium.7

Keadaan ini berubah setelah kekuasaan beralih ke tangan Dinasti Abbasiyah. Pada masa ini muncul imam-imam mujathid. Karena itu periode ini disebut juga periode imam-imam mujtahid, yang berlangsung kurang lebih 250 tahun (101350H/750-961M). Hukum Islam pada masa ini mulai berjalan dalam kekuatan yang padu antara ulama dan umara. Hukum Islam menjalar ke wilayah yang luas. Para imam mujathid --dalam suasana yang kondusif-- berusaha menghimpun dan menelaah bahan-bahan yang diwariskan oleh generasi pendahulunya. Mereka juga membukukan hadis-hadis, fatwa-fatwa sahabat, fatwa-fatwa Tabi'in. Di samping itu

\footnotetext{
${ }^{6}$ Lihat, Anwar Haryono, Hukum Islam Keluasan dan Keadilannya, h. 56.

${ }^{7}$ Anwar Haryono, Hukum Islam Keluasan dan Keadilannya, h. 56.
} 
mereka juga berusaha meletakkan dasar-dasar fiqh (ushul fiqh) dan ilmu mustalah alHadis. ${ }^{8}$

Usaha-usaha imam-imam mujathid di atas tampaknya didorong oleh beberapa faktor, di antaranya; (1) agar masyarakat lebih mudah memperoleh informasi mengenai hukum Islam. Dengan demikian, penerapan hukum Islam dalam berbagai aspek kehidupan lebih mudah, (2) untuk menghindari kemungkinan munculnya pemalsuan hadis yang menyebabkan kesulitan dan kelambatan dalam istimbat hukum, (3) untuk melestarikan karya ulama terdahulu sebagai warisan yang bernilai tinggi kepada generasi-generasi kemudian, dan (4) untuk menyingkirkan kebodohan dari umat Islam.

Imam-imam mujtahid ternama pada periode ini di antaranya, Sufyan bin Uyainah di Mekkah, Malik bin Anas di Madinah, Hasan Al-Basri di Basrah, Abu Hanifah dan Sufyan Tsauri di Kufa, dan Al-Auza'i di Syiria. Syafi'i dan Laits bin Sa'ad di Mesir, Ishak bin Rahaweh di Naisabur, serta Abu Tsaur, Ahmad bin Hambal, Dawud Az-Zahiri, dan Ibnu Jarir di Bagdad.9

Mazhab ketigabelas mujtahid tersebut dibukukan dan pendapatnya diikuti. Jumhur ulama mengakui mereka sebagai tokoh fiqh dan sebagai panutan. Karena itu, masa ini dapat dikatakan juga sebagai puncak kegemilangan ilmu fiqh. ${ }^{10}$

\section{E. FAKTOR-FAKTOR PERTUMBUHAN DAN PERKEMBANGAN HUKUM}

Kemajuan yang dicapai hukum Islam dalam periode ini tidak terlepas dari situasi dan kondisi sosial politik. Demikian pula semangat dan dinamika keilmuan yang semakin berkembang, turut memberi andil bagi kemajuan hukum Islam.

Secara ringkas, penulis akan mengemukakan beberapa faktor yang berpengaruh terhadap perkembangan hukum Islam.

\section{Perhatian Para Khalifah Terhadap Fiqh dan Fuqaha}

Seperti telah diuraikan pada bagian terdahulu bahwa beralihnya kekuasaan dari bani Umayyah ke Bani Abbasiyah telah membawa perubahan berarti bagi pertumbuhan dan perkembangan hukum Islam. Hal ini dimungkinkan karena para khalifah Abbasiyah menaruh perhatian besar terhadap kehidupan agama. Mereka berusaha agar daulah tersebut berdiri di atas dasar undang-undang yang diambil dari fiqh Islam. Karena itu kebutuhan terhadap fiqh menjadi sangat mendesak.11

Kebutuhan mendesak mereka terhadap fiqh mempengaruhi pandangan mereka terhadap fuqaha. Mereka memberi tempat khusus bagi para fuqaha. Mereka sangat menghargai dan mengistimewakannya. Abu Ja'far al-Manshur, misalnya, memberi hadiah kepada mereka. Al-Mahdi dan khalifah sesudahnya menjauhkan kaum

\footnotetext{
${ }^{8}$ Lihat, Muhammad Yusuf Musa, al-Islam wa Khair al-Insaniyah. Diterjemahkan oleh A. Malik Madaniy dan Hamim dengan judul, Islam suatu Kajian Komprehensip (Jakarta: Rajawali Press, 1988), h. 68.

${ }^{9}$ Muhammad Ali As-Sayis, Tarikh al-Fiqh al-Islami, h. 124.

${ }^{10}$ Muhammad Ali As-Sayis, Tarikh al-Fiqh al-Islami, h. 157.

${ }^{11}$ Muhammad Yusuf Musa, Muhammad Yusuf Musa, al-Islam wa Khair al-Insaniyah, h. 157.
} 
zindiq dan menyiksanya. Sementara Al-Rasyid menjadikan Abu Yusuf sebagai teman pergaulan dan Al-makmun bergaul bersama ulama dalam diskusi ilmiah.12

Perlakuan khusus para khalifah terhadap fuqaha menyebabkan fuqaha lebih leluasa dalam berfikir, berpendapat dan berkarya. Situasi ini sangat kontras dengan situasi pada masa Bani Umayyah. Pada masa itu, fuqaha sangat terkungkung kebebasannya dalam berpendapat. Kalaupun mereka mengeluarkan fatwa-fatwa, harus berdasarkan kepentingan politik tertentu.

\section{Kebebasan berfikir}

Kebijakan khalifah-khalifah Abbasiyah untuk tidak melakukan tekanantekanan kepada fuqaha, membuat fuqaha lebih bebas dalam berfikir dan mengeluarkan pendapatnya.13 Tidak ada rasa takut yang selalu menghantui. Karena itu mereka dapat berijtihad dengan tenang tanpa dibatasi oleh suatu kekuatan yang mengkungkung pendapatnya. Mereka benar-benar menikmati kebebasan berfikir. Itu sebabnya mereka mampu melahirkan karya-karya besar yang sebagian di antaranya masih dapat dinikmati saat ini.

Sumber rujukan mereka dalam berijtihad adalah Al-Qur'an dan Sunnah Rasulullah. Dari dua rujukan tersebut mereka berijtihad dengan kemampuan masing-masing. Akibatnya, apabila satu masalah dihadapkan kepada para fuqaha akan dapat diperoleh lebih dari satu fatwa hukum. Begitu pula dalam hal-hal yang tidak berkaitan dengan peradilan, misalnya masalah ibadah, yang tentu saja permasalahannya yang bersifat ijtihadiyah.

Dari kenyataan tersebut, terlihat dengan jelas betapa kebebasan berfikir telah membawa nuansa kedinamisan hukum Islam. Dengan beragamnya pendapat atau fatwa yang dikemukakan oleh fuqaha akan memperkaya khazanah bagi perkembangan dan pertumbuhan hukum Islam. Meskipun untuk kalangan tertentu dapat menilai kenyataan ini sebagai sesuatu yang kurang baik bagi pelaksanaan hukum Islam oleh masyarakat.

\section{Banyak Perdebatan}

Sebagai buah dari kebebasan berfikir dan berpendapat, pada periode ini muncul berbagai perdebatan. Hal ini disebabkan para ulama --dengan kebebasan yang dimilikinya-- berijtihad sesuai dengan kemampuan masing-masing. Perdebatan-perdebatan ini juga dipicu oleh banyaknya ulama dan meningkatnya taraf pemikiran.

Perdebatan-perdebatan antara para ulama berkisar pada pembatasan makna lafaz bahasa, arti hakikat dan majaz, hubungan Al-Qur'an, Sunnah dengan lainnya, perbuatan sahabat apakah merupakan hujjah atau bukan, qiyas dan jangkauannya, dan lain-lain.

Perdebatan itu terkadang dilakukan secara lisan di halaqah belajar, di rumah,

\footnotetext{
12 Muhammad Ali As-Sayis, Tarikh al-Fiqh al-Islami, h. 125.

${ }^{13}$ Muhammad Ali As-Sayis, Tarikh al-Fiqh al-Islami, h. 125.
} 
atau di Masjid. Hal tersebut memberi sumbangan positif bagi kemajuan kegiatan ilmiah di kemudian hari. ${ }^{14}$

\section{Banyak peristiwa dan Budaya yang beragam}

Semakin meluasnya wilayah kekuasaan Islam sebagai hasil dari ekspansi besar-besaran Dinasti Umayyah menyebabkan timbulnya berbagai masalah. Masalah-masalah itu muncul, di samping karena banyaknya penganut Islam yang baru juga karena beragamnya budaya di daerah-daerah yang dikuasai.

Banyaknya persoalan yang muncul tersebut mendorong para fuqaha untuk membahasnya. Dengan demikian penduduk mengetahui hukumnya dan hidup mereka diwarnai dengan agama tersebut. Di Irak, fuqaha dihadapkan pada adat kebiasaan Parsi. Di Syiria, Al-Auza'i dan kawan-kawannya dihadapkan dengan adat kebiasaan yang bercorak Rumawi. Demikian pula di Mesir Laits bin Sa'ad dan Syafi'i dihadapkan dengan adat istiadat campuran Mesir dan Rumawi. ${ }^{15}$

\section{Pembukuan Ilmu Pengetahuan}

Pembukuan ilmu pengetahuan merupakan konsekwensi lanjut dari faktorfaktor yang telah disebutkan. Meskipun demikian, faktor ini dianggap sebagai sebab kebangkitan ilmiah itu sendiri.

Pembukuan pada periode ini tidak terbatas pada fiqih, meskipun fiqih merupakan prioritas. Dengan adanya pembukuan ini, pekerjaan para ulama menjadi lebih mudah karena merujuk pada kodifiksi tersebut. Di antara ilmu-ilmu yang dibukukan adalah Tafsir dan Sunnah Rasulullah saw. Kduanya sangat dibutuhkan oleh fuqaha dalam menyusun fiqih. ${ }^{16}$

\section{F. MAZHAB EMPAT DAN PEMIKIRANNYA}

Dalam khazanah fiqh dikenal empat mazhab yang cukup populer. Mazhabmazhab tersebut lahir dari mujtahid-mujtahid besar periode ini. Mereka adalah Imam Abu Hanifah (Mazhab Hanafiah), Imam Malik (Malikiyah), Imam Syafi'i (Syafi'iyyah) dan Imam Ahmad bin Hambal (Hambaliyah).

\section{Imam Abu Hanifah}

Abu Hanifah ${ }^{17}$ termasuk pengikut tabi'in. Ia hidup disaat empat orang sahabat masih ada, yaitu Anas bin Malik di Basrah, Abdullah bin Abi Aufa di Kufa, Sahl bin Sa'ad As-Sa'idi di Madinah, dan At-Tufail Amir bin Watsilah di Mekkah. Hanya saja, di antara empat orang sahabat tersebut yang sempat bertemu dengannya hanya Anas bin Malik.

\footnotetext{
${ }^{14}$ Muhammad Ali As-Sayis, Tarikh al-Fiqh al-Islami, h. 126.

${ }^{15}$ Muhammad Ali As-Sayis, Tarikh al-Fiqh al-Islami, h. 128.

${ }^{16}$ Muhammad Ali As-Sayis, Tarikh al-Fiqh al-Islami, h. 128,

${ }^{17}$ Nama lengkapnya adalah An-Nukman bin Tsabit bin Zutha bin Mahmuli Tayimullah bin Tsa'labah. Ia lahir pada tahun $80 \mathrm{H}(659 \mathrm{M})$ di Kufa. Lihat, Muhammad Ali As-Sayis, Tarikh al-Fiqh al-Islami, h. 136. K.H. Moenawar Chalil, Biografi Empat Serangkai Imam Mazhab (Cet. V; Jakarta: Bulan Bintang, 1986), h. 19. Data kelahiran Imam Abu Hanifah dalam buku ini adalah tahun 80 H (699M).
} 
Sumber syari'at Islam bagi Abu Hanifah adalah Al-Qur'an dan Al-Sunnah, sebagaimana ulama lainnya. Hanya saja Abu Hanifah sangat hati-hati dalam menerima hadis atau riwayat. Ia tidak menerima suatu riwayat kecuali riwayat itu berasal dari jama'ah atau riwayat itu disepakati oleh fuqaha suatu negeri dan diamalkan. Riwayat lain yang diterimanya adalah riwayat ahad yang diriwayatkan oleh sahabat dalam jumlah banyak, tetapi belum mencapai derajat mutawatir, yang tidak dipertentangkan. ${ }^{18}$

Kehati-hatian Imam Abu Hanifah dalam menerima riwayat dan lebih banyak menggunakan ra'yu (ijtihad) menyebabkan ia digolongkan sebagai ahl al-ra'yu. Ini disebabkan karena kurangnya riwayat yang sampai kepadanya.

Langkah ijtihad yang ditempuh oleh Abu Hanifah dapat dipahami dari ungkapannya sebagai berikut:

"Sesungguhnya saya memberikan hukum berdasarkan Al-Qur'an. Apabila tidak saya jumpai di dalam Al-Qur'an, saya gunakan sunnah dan atsar Rasulullah (sahabat?) yang shahih yang tersebut di kalangan orang-orang handal (tsiqah). Apabila saya tidak dapatkan dari keduanya (Al-Qur'an dan Sunnah), saya berpegang pada pendapat siapa saja dari sahabat Rasulullah yang saya sukai dan saya tinggalkan yang tidak saya sukai, dan saya tidak beralih dari pendapat mereka kepada pendapat selainnya, serta apabila permasalahan telah sampai kepada ibrahim, Asy-Sya'bi, Al-Hasan, Ibnu Sirin dan Sa'id bin Al-Musayyab, saya berijtihad sebagaimana mereka berijtihad. ${ }^{19}$

Dari ungkapan tersebut dapat dipahami bahwa Imam Abu Hanifah dalam mengeluarkan pendapat-pendapatnya, menggunakan Al-Qur'an dan Sunnah sebagai landasan. Namun bila dalam keduanya tidak ditemukan, ia menggunakan pendapat-pendapat sahabat yang ia senangi dan meninggalkan yang lain. Kalaupun ia belum menemukannya ia berijtihad sesuai kemampuan yang ia miliki. Ia tidak akan mengambil pendapat-pendapat yang dikeluarkan oleh ulama yang ia anggap selevel dengannya.

Kalimat sahabat yang ia senangi sebenarnya secara sepintas menyiratkan sifat pilih kasih Abu Hanifah terhadap para sahabat Rasul. Namun demikian sudah barang tentu ia memiliki alasan mengapa ia menyukai sahabat yang satu dan membenci sahabat yang lain.

Abu Hanifah adalah orang pertama yang sibuk dengan fiqih prediksi, yakni memaparkan permasalahan yang belum terjadi dan menjelaskan hukumhukumnya dengan harapan bila peristiwa itu terjadi maka hukumnya telah tersedia. ${ }^{20}$

${ }^{18}$ Dr. Muh. Zuhri, Hukum Islam Dalam Lintasan Sejarah (Cet. I; Jakarta: PT. Raja Grafindo Persada, 1996), h. 98.

${ }^{19}$ Muhammad Ali As-Sayis, Tarikh al-Fiqh al-Islami, h. 141.

${ }^{20}$ Muhammad Ali As-Sayis, Tarikh al-Fiqh al-Islami, h. 142. 


\section{Imam Malik}

Nama lengkapnya adalah Malik bin Anas bin Malik bin Abu Amir AlAshbahi. Ia lahir di Madinah pada $93 \mathrm{H}$ dan menuntut ilmu kepada ulama Madinah. Orang pertama yang dipergaulinya adalah Abdurrahman bin Hurmuz. Gurunya dalam bidang fiqh adalah Rabi'ah bin Abdurrahman yang dikenal dengan Rabi'ah Ar-Ra'yu. ${ }^{21}$

Sandaran ijtihad Imam Malik adalah Al-Qur'an, Sunnah, Ijma dan qiyas. Di samping itu, Imam Malik juga menawarkan ijtihad dalam bentuk al-maslahah almursalah. Teori ini diilhami oleh suatu paham bahwa syari'at Islam bertujuan untuk mendatangkan manfaat, kesejahteraan dan kedamaian bagi kepentingan masyarakat dan mencegah kemudaratan. Menurutnya, kepentingan bersama merupakan sasaran Syari'at Islam. Semua produk hukum memprioritaskan kepentingan bersama di atas kepentingan pribadi. ${ }^{22}$

Imam Malik secara umum mengikuti cara orang-orang Hijaz dalam menempatkan atsar selagi mungkin. Ia --berbeda dengan Imam Abu Hanifah-membenci memprediksi dan memaparkan masalah yang belum terjadi.

\section{Imam Syafi'i}

Nama lengkap Imam Syafi'i adalah Abu Abdillah Muhammad bin Idris bin Al-Abbas bin Utsman bin Syafi'i Al-Hasyimi Al-Muthalibi. Ia berasal dari keturunan Bani Muthalib bin Abdi Manaf, yang juga kakek Rasulullah. Ia dilahirkan di kota Ghazza di wilayah Syiria pada tahun $150 \mathrm{H} .{ }^{23}$

Landasan ijtihad Imam Syafi'i adalah Al-Qur'an dan al-Sunnah. Apabila dalam keduanya tidak ada, maka ia mengqiyaskan (analogi) terhadap keduanya. Bila berkaitan dengan dengan hadis Rasulullah dan sanadnya shahih, maka itulah tujuan akhir. Ijama' adalah lebih kuat daripada khabar ahad dan hadis berdasar makna zahirnya. Apabila hadis mengandung dua pengertian, ia mendahulukan makna yang menyerupai zahirnya. Apabila keduanya sama, maka yang didahulukan adalah hadis yang sanadnya yang paling shahih (valid).

Syafi'i memandang sunnah yang shahih wajib diikuti sebagaimana AlQur'an. Beliau tidak menetapkan syarat buat hadis seperti yang diberikan oleh Imam Abu Hanifah maupun oleh Imam Malik. ${ }^{24}$ Ia hanya mensyaratkan shahih dan itishal (bersambung-sambung sanandnya). Ia juga sangat mempertahankan beramal dengan Khabar Ahad yang shahih. Sikap ini membuatnya disenangi di kalangan ahli hadis dan ia diberi gelar Nashirus Sunnah (penolong sunnah). ${ }^{25}$

${ }^{21}$ Muhammad Ali As-Sayis, Tarikh al-Fiqh al-Islami, h. 146. K.H. Moenawar Chalil, Biografi Empat Serangkai Imam Mazhab, h. 19

22 Dr. Muh. Zuhri, Hukum Islam Dalam Lintasan Sejarah, h. 107.

${ }^{23}$ Muhammad Ali As-Sayis, Tarikh al-Fiqh al-Islami, h. 154. K.H. Moenawar Chalil, Biografi Empat Serangkai Imam Mazhab, h. 25.

${ }^{24}$ Abu Hanifah mensyaratkan hadis yang dapat diterima adalah hadis masyhur sedang Imam Malik adalah hadis yang tidak menyalahi amalan penduduk Madinah.

${ }_{25}$ Muhammad Ali As-Sayis, Tarikh al-Fiqh al-Islami, h. 158. 


\section{Imam Ahmad bin Hambal}

Nama lengkapnya adalah Abu Abdullah bin Hambal bi Hilal bin Asad AsySyaebani Al-Mawarzi Al-Baghdadi.Ia lahir di Baghdad pada tahun $164 \mathrm{H}$. Ia berusaha mengumpulkan sunnahdan menghafalnya hingga menjadi imam ahli hadis pada masanya. Imam Ahmad bin Hambal adalah murid tertua Imam Syafi'i dari kalangan orang Baghdad. ${ }^{26}$

Landasan ijtihad Imam Ahmad hampir sama dengan prinsip Syafi'i. Ibnu AlQayyim dalam kitab I'lam Al-Muwaqi'in --sebagaimana dikutip As-Sayis-menyebutkan bahwa fatwa-fatwa Ahmad bin Hambal berdasar pada: (1) AlQur'an dan hadis marfu', (2) Fatwa sahabat, (3) Pendapat sahabat yang lebih dekat pada Kitabullah dan sunnah, (4) Hadis Mursal dan Hadis Dhaif (lemah) apabila dalam bab itu tak ada sesuatu yang menolaknya, dan (5) Al-Qiyas (Analogi). Prinsip ini menurutnya digunakan ketika tidak mendapatkan hadis, qaul Sahabi, hadis mursal atau dhaif. ${ }^{27}$

\section{G. KESIMPULAN}

Pada masa kodifikasi dan Imam-imam mujtahid, hukum Islam, dalam pertumbuhan dan perkembangannya memperoleh peluang yang sangat luas. Situasi politik yang tercipta setelah peralihan kekuasaan dari Bani Umayyah kepada bani Abbasiyah sangat menguntungkan. Bila sebelumnya para ulama dikungkung kebebasannya dalam berpendapat, kecuali sesuai dengan pandangan politik penguasa, maka pada periode ini ulama memperoleh kebebasan yang besar dari para penguasa (khalifah) Abbasiyah. Itulah sebabnya banyak karya yang lahir pada masa ini.

Di samping situasi politik, perkembangan hukum Islam yang mencapai puncak kegemilangan pada periode ini, turut didukung oleh berbagai faktor, diantaranya banyaknya peristiwa dan perdebatan di kalangan para ulama.

${ }^{26}$ Muhammad Ali As-Sayis, Tarikh al-Fiqh al-Islami, h. 161. K.H. Moenawar Chalil, Biografi Empat Serangkai Imam Mazhab, h. 56

${ }^{27}$ Muhammad Ali As-Sayis, Tarikh al-Fiqh al-Islami, h. 164. 


\section{Daftar Pustaka}

Badran, Badran Abu al-'Ainain. Ushul Figh al-Islamiy. Mesir: Muassasah Syabab alJami'ah al-Iskandariyah, t.th.

Chalil, K.H. Moenawar. Biografi Empat Serangkai Imam Mazhab. Cet. V; Jakarta: Bulan Bintang, 1986.

Haroen, Nasrun. Ushul Figh 1. Cet. II; Jakarta: Logos Wacana Ilmu, 1997.

Haryono, Dr. Anwar, S.H. Hukum Islam Keluasan dan Keadilannya. Jakarta: Bulan Bintang, 1987.

Musa, Muhammad Yusuf. al-Islam wa Khair al-Insaniyah. Diterjemahkan oleh A. Malik Madaniy dan Hamim dengan judul, Islam suatu Kajian Komprehensip. Jakarta: Rajawali Press, 1988.

As-Sayis, Syekh Muhammad Ali. Tarikh al-Figh al-Islami. Diterjemahkan oleh Dedi Junaedi dengan judul Sejarah Pembentukan dan Perkembangan Hukum Islam. Jakarta: Akademika Pressindo, 1996

Ya'kub, Hamzah. Pengantar Ilmu Syari'ah (Hukum Islam). Cet. IX; Bandung: CV. Diponegoro, 1995.

Zuhri, Dr. Muh. Hukum Islam Dalam Lintasan Sejarah. Cet. I; Jakarta: PT. Raja Grafindo Persada, 1996. 